\title{
Addendum to NuMI Shielding Assessment
}

October 2007

Kamran Vaziri

\section{Introduction}

The original safety assessment and the Safety Envelope for the NuMI beam line corresponds to $400 \mathrm{~kW}$ of beam power ${ }^{1}$. The Main Injector is currently capable of and approved for producing $500 \mathrm{~kW}$ of beam power ${ }^{2}$. However, operation of the NuMI beam line at $400 \mathrm{~kW}$ of power brings up the possibility of an occasional excursion above 400 $\mathrm{kW}$ due to better than usual tuning in one of the machines upstream of the NuMI beam line. An excursion above the DOE approved Safety Envelope will constitute a safety violation.

The purpose of this addendum is to evaluate the radiological issues and modifications required to operate the NuMI beam line at $500 \mathrm{~kW}$. This upgrade will allow $400 \mathrm{~kW}$ operations with a reasonable safety margin. Configuration of the NuMI beam line, boundaries, safety system and the methodologies used for the calculations are as described in the original NuMI SAD ${ }^{1,3}$. While most of the calculations presented in the original shielding assessment were based on Monte Carlo simulations, which were based on the design geometries, most of the results presented in this addendum are based on the measurements conducted by the AD ES\&H radiation safety group.

\section{Radiological Concerns}

Safety issues are an important consideration for NuMI upgrades and operations. Fermilab is committed to maintaining a safe work place, minimizing worker exposure to radioactive material, and protecting the environment. Radiological concerns are of particular concern for the NuMI beam line given the intensity of protons directed on the target.

Potential environmental impacts include radioactive air emissions, groundwater protection, tritium production, prompt radiation doses, residual activation of the equipment, radiation from the primary RAW systems and radioactive waste disposal.

\section{Earth Shielding}

The NuMI extraction line would require $23.2 \mathrm{ft}$. of earth shielding for the $500 \mathrm{~kW}$ operation of $9.63 \mathrm{E} 16$ protons/hr, if the berm is categorized as minimal occupancy ${ }^{2}$. This is based on assuming beam line to ceiling distance of 3 feet. The present shielding for the NuMI extraction line is more than this, 24.5 feet. Because of the 3.3 degrees down slope of the carrier pipe, there is sufficient earth shielding for the rest of this beam line. 


\section{Ground Water Protection and Monitoring}

\section{Ground and surface water activation}

The NuMI Tunnel enters the groundwater aquifer near the Hobbit door ${ }^{4,5}$ (see Fig. 1). Portions of the tunnel upstream of the Hobbit door are lined with concrete; downstream of the Hobbit door the NuMI tunnel is located in rock (dolomite). The water naturally flows down the floor drains and into the sump at the base of the MINOS shaft, where it is pumped to the surface. This includes the water outside the lined section of the carrier tunnel, which is captured by the unlined section of the carrier tunnel. During operation, the NuMI beam line losses are monitored by interlocked radiation detectors and minimized to keep water activation and residual dose rates in the tunnel below limits defined in the FRCM ${ }^{6}$. The beam permit system ${ }^{7}$ helps prevent repetitive beam losses by looking at the quality of the MI beam, losses on the last extracted pulse and readiness of the NuMI beam line. These two systems make it extremely unlikely that beam loss at the level of 1 part in $10^{5}$ will occur for more than a couple of pulses.

Water flowing into the NuMI tunnel is pumped to the surface from the sump pump area at the base of the MINOS shaft. At the surface, the water is discharged to either the FNAL industrial cooling water (ICW) system or the pond at the MINOS service building. A monitoring well (S-1274) down gradient of the carrier tunnel region is sampled periodically in accordance with Fermilab Ground Water Monitoring Strategy ${ }^{8}$. The approved method for monitoring as to whether one is within the limits is by monitoring wells for groundwater and surface sampling for surface waters. Verification that such limits are not violated is accomplished during the facility operation through the Lab-wide monitoring program. The sumps for the NuMI beam line are sampled periodically in accordance with the Routine Monitoring Program procedure ${ }^{9}$ ADDP-SH-1003.

Measurements ${ }^{10}$ at the NuMI well show no detectable tritium or ${ }^{22} \mathrm{Na}(<0.2 \mathrm{pCi} / \mathrm{ml}$ and $<0.03$, respectively) after 2.05E20 protons on the NuMI Target. $500 \mathrm{~kW}$ operations corresponds to $9.63 \mathrm{E} 16$ protons/hr on target or $25 \%$ more integrated beam. For a credible worst-case scenario we assume the tritium levels scale with integrated beam. If all tritium leached out of the rock as the water flowed into the NuMI tunnel, one would expect the tritium levels to scale with instantaneous beam intensity instead of integrated intensity. Thus we will (conservatively) scale with integrated protons on target. Table 1 shows the regulatory limits, measured values and the projections for tritium and ${ }^{22} \mathrm{Na}$ levels in NuMI sump (surface water) and the NuMI well (groundwater). The last two columns show the predicted concentrations of tritium and ${ }^{22} \mathrm{Na}$ for $5 \mathrm{E} 20$ protons per year.

An additional source of tritium is from the shielding in the Target Chase. The oxygen atoms in the chase cooling air can pick up the triton atoms produced and trapped in the shielding. This source is apparent during the long shut downs where running the Target Chase fans will increase the air concentration of HTO, which in turn shows up in the sump water. This source is proportional to the total protons on target ${ }^{11}$. Measurements ${ }^{12}$ indicate that the rate of diffusion of tritium out of the shielding is much slower than the ${ }^{3} \mathrm{H}$ production rate in the shielding. Table 2 shows the resultant total concentrations of tritium in the sump water due to the addition of this internal source, assuming no further mitigations. 
The sum of the tritium and ${ }^{22} \mathrm{Na}$ concentrations relative to the limits is less than one. The combined concentrations of ${ }^{22} \mathrm{Na}$ and ${ }^{3} \mathrm{H}$ are $12 \%$ and $2 \%$ of the groundwater and the

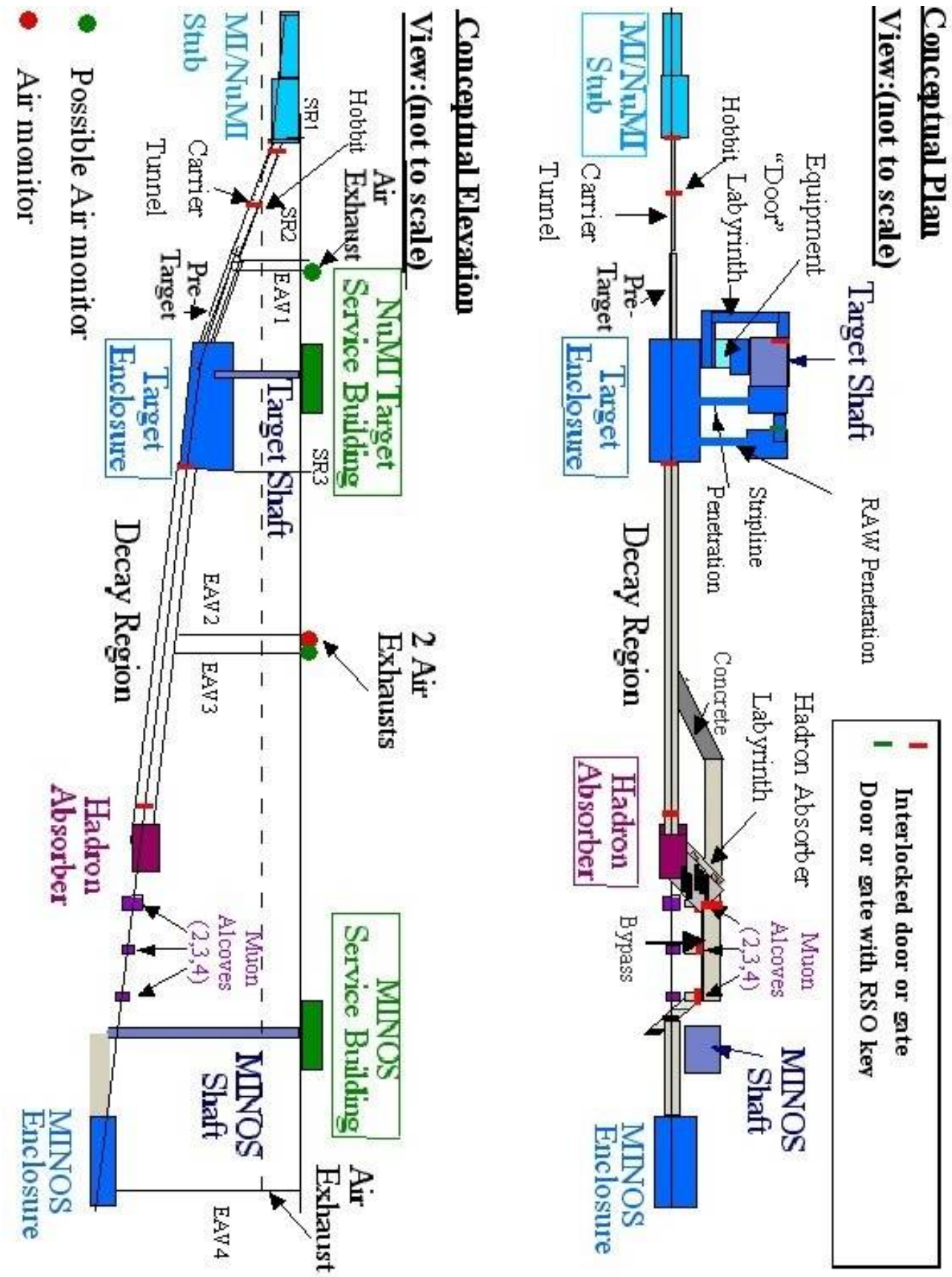

Figure 1. Conceptual plan and elavation views of the NuMI Project.

surface water limits, respectively. For ${ }^{22} \mathrm{Na}$, where our level of detection is not low enough for us to extrapolate without going over the limit, predictions are more difficult. Clearly since less than $0.03 \mathrm{pCi} / \mathrm{ml}$ are typically measured in the sump for ${ }^{22} \mathrm{Na}$, then the 
monitoring well will have significantly smaller concentrations. In reality, the likelihood of any water from the large NuMI tunnel making it away from the tunnel is extremely small. If any did reach a monitoring well, if would be diluted with other water and not be measurable.

The extremely unlikely catastrophic loss of the RAW from any of the NuMI cooling systems does not cause any significant increase to the concentration of radionuclides in the discharge to the surface waters ${ }^{13}$ and results, conservatively, in a release of water at $5.6 \%\left(5.1 \%{ }^{7} \mathrm{Be}, 0.5 \%{ }^{3} \mathrm{H}\right)$ of the surface discharge limit. The controls, interlocks and alarms designed for these systems prevent any catastrophic losses and damage to the equipment as well.

\begin{tabular}{|c|c|c|c|c|c|c|}
\hline & \multicolumn{2}{|c|}{$\begin{array}{c}\text { Regulatory } \\
\text { Limits (pCi/ml) }\end{array}$} & \multicolumn{2}{|c|}{$\begin{array}{l}\text { Measured } \\
(\mathrm{pCi} / \mathrm{ml})\end{array}$} & \multicolumn{2}{|c|}{$\begin{array}{l}\text { Extrapolation to } 500 \mathrm{~kW} \\
(\mathrm{pCi} / \mathrm{ml})\end{array}$} \\
\hline & GW & SW & GW & Sump & GW & Sump \\
\hline${ }^{3} \mathrm{H}$ & 20 & 2000 & $<0.2$ & 6 & $<0.5$ & 15 \\
\hline${ }^{22} \mathrm{Na}$ & 0.4 & 10 & $<0.01$ & $<0.03$ & $<0.045$ & $<0.1$ \\
\hline $\begin{array}{l}\text { Integrated protons } \\
\text { on target }\end{array}$ & & & \multicolumn{2}{|c|}{$2.05 E+20$} & $5.00 \mathrm{E}+20$ & PoT/yr \\
\hline
\end{tabular}

Table 1. Measurements and Projections for Tritium and ${ }^{22} \mathrm{Na}$. With the exception of ${ }^{3} \mathrm{H}$ in the NuMI sump water, all measured values were below detectable limits. Values quoted as less than, were below detectable limits. Therefore scaling of these concentrations to higher beam power can only provide upper limits.

\begin{tabular}{|c|c|c|c|}
\hline Year & Total POT & POT / yr & $\begin{array}{c}\text { Average daily } \\
(\mathrm{pCi} / \mathrm{ml})\end{array}$ \\
\hline 2005 & $1.00 \mathrm{E}+20$ & $1.00 \mathrm{E}+20$ & 3.0 \\
\hline 2006 & $1.80 \mathrm{E}+20$ & $8.00 \mathrm{E}+19$ & 4.5 \\
\hline 2007 & $3.60 \mathrm{E}+20$ & $1.80 \mathrm{E}+20$ & 9.2 \\
\hline 2008 & $6.60 \mathrm{E}+20$ & $3.00 \mathrm{E}+20$ & 16.6 \\
\hline 2009 & $1.06 \mathrm{E}+21$ & $4.00 \mathrm{E}+20$ & 26.0 \\
\hline
\end{tabular}

Table 2. Projections for Tritium in the NuMI sump water including the contribution from the Target Chase, which is dependent on the total protons on target.

\section{Radioactive Air Emissions}

Currently the activated air from NuMI areas is released from the Stacks EAV1, EAV2, EAV3 and SR3 ${ }^{17}$. The total tritium and non-tritium radioisotopes air emissions from NuMI areas, under the current configuration are estimated for the $500 \mathrm{~kW}$ operations. Estimates are based on measurements, except for SR3 stack (see Fig. 2) where a conservative estimate has been used. 


\section{Non-tritium isotopes emitted from the stacks}

Usually ${ }^{15} \mathrm{O}$ (122.2 sec.), ${ }^{13} \mathrm{~N}$ (10min), ${ }^{11} \mathrm{C}(20 \mathrm{~min}),{ }^{41} \mathrm{Ar}$ (1.8hrs) and some times ${ }^{38} \mathrm{Cl}$ (37.2min) and ${ }^{39} \mathrm{Cl}(55.5 \mathrm{~min})$ are detected at the stacks. Because of relatively long transit times from the production point to the stack (20min to hours) shorter-lived isotopes are not observed. Since the transit time through SR3 is only 2.4 seconds, short-lived isotopes can reach the release point and the SR3 stack air monitor. Because of the short transit time from the NuMI target hall to the release point of SR3, the isotopes ${ }^{14} \mathrm{O}(71 \mathrm{sec}),{ }^{19} \mathrm{O}$ $(27.1 \mathrm{sec})$ and ${ }^{40} \mathrm{Cl}(1.4 \mathrm{~min})$, will reach the top of the stack. Assuming, conservatively, that these short-lived isotopes are produced with the same cross section as the more common species, the ratios of short-lived to the longer-lived isotopes at the site boundary can be estimated. The results show that ${ }^{14} \mathrm{O} /{ }^{15} \mathrm{O}$ fraction is about $14 \%,{ }^{19} \mathrm{O} /{ }^{15} \mathrm{O}$ is 4 orders of magnitude smaller and ${ }^{40} \mathrm{Cl} /{ }^{38} \mathrm{Cl}$ is about $2 \%$. Note that ${ }^{13} \mathrm{~N}$ and ${ }^{11} \mathrm{C}$ are usually $90 \%$ of the total release at the stack point. All the other isotopes are less than $10 \%$. Therefore, fractions of $10 \%$ will not affect the site boundary dose significantly. Table 3 shows the total estimated activity release from the NuMI stacks at $500 \mathrm{~kW}$, extrapolated from measurements at $140 \mathrm{~kW}$. A release of 52.2 Curies of radionuclides corresponds to an annual dose equivalent of 23 micro-rem at the Fermilab site boundary.

\begin{tabular}{|l|c|c|}
\cline { 2 - 3 } \multicolumn{1}{c|}{} & $\begin{array}{c}\text { measurements } \\
\text { at } 140 \mathrm{~kW} \\
\mathrm{Ci} / \mathrm{yr}\end{array}$ & $\begin{array}{c}\text { Scaled to } \\
500 \mathrm{~kW} \\
\mathrm{Ci} / \mathrm{yr}\end{array}$ \\
\hline EAV1 & 2.0 & 7.0 \\
\hline EAV2 & 6.0 & 21.4 \\
\hline EAV3 & 4.0 & 14.4 \\
\hline SR3 (est.) & 2.6 & 9.4 \\
\hline Total(Ci) & 14.6 & 52.2 \\
\hline
\end{tabular}

Table 3. A radioactive air emission estimates from the stacks.

\section{Tritium release from the stacks}

Airborne tritium is released from the EAV1, EAV2, EAV3, SR3 and MI-65 ${ }^{18}$ stacks. The condensate from the Target Chase air chillers is extracted and pumped to a boiler in the MI-65 building. This water is then boiled and released from the MI-65 stack. In October 2005, during the periods that NuMI experiment was operating at less than $150 \mathrm{~kW}$, and before the installation of the Target Hall dehumidification system and the removal chiller condensate from the inflow, all of the tritium ended up in the holding tank. The maximum tank concentration observed at this time was $27.9 \mathrm{pCi} / \mathrm{ml}$. The water inflow rate was 177 gallons per minute. This corresponds to about 9.8 Curies of tritium per year. Assuming, conservatively, that all of this tritium is released to the air, at $500 \mathrm{~kW}$ beam power, this will result in about 32.7 Curies of tritium in a year from this source. Another source of the tritium is from buildup and purge of the Decay Pipe helium ${ }^{19}$. Reference 19 describes the normal operating condition of the Decay Pipe helium system. It is estimated that annually a maximum of 25.6 Curies may be released from this source, through the EAV3 stack. This will correspond to a maximum total of 58.3 Curies of tritium release per year. 
Total tritium release will contribute about 0.4 micro-rem in a year to the site boundary dose. Most of the tritiated moisture from the Target Hall air is extracted and diverted to SR3 stack. The area around the SR3 stack is considered to be minimal occupancy. A person breathing the SR3 air for 250 hours in a year will receive $21.3 \mathrm{mrem}$, which is below the 100 mrem in a year allowable for a member of the public. The MI-65 stack is located on the roof of MI-65 building. The roof is generally inaccessible. Experience with SR3 proves that the design provides for very well dispersion of the effluents high into the atmosphere. Workers at the ground level around the MI-65 service building will not be exposed to the tritium vapor. An accidental release of the Decay Pipe helium into the Target Hall, after the first year of operation under any operating scenario ${ }^{19}$, will result in less than 100 mrem dose to a worker. After the fist year of operation the decay pipe has to be purged often enough so as not to exceed the operational dose limit of $100 \mathrm{mrem} / \mathrm{hr}$ per accident.

These conservative estimates indicate that the total radioactive air emissions from 500 $\mathrm{kW}$ operations do not require any revisions to the laboratory's permits or monitoring methodologies. Air released from EAV1, EAV2, EAV3 and SR3 is periodically sampled and characterized. The MI-65 water is periodically sampled and the tritium concentration is logged to be used for the annual release calculations. Similarly, the tritium concentration in helium will be measured by sampling the DP helium several times during the operating year, by the ES\&H Radiation Physics Team.

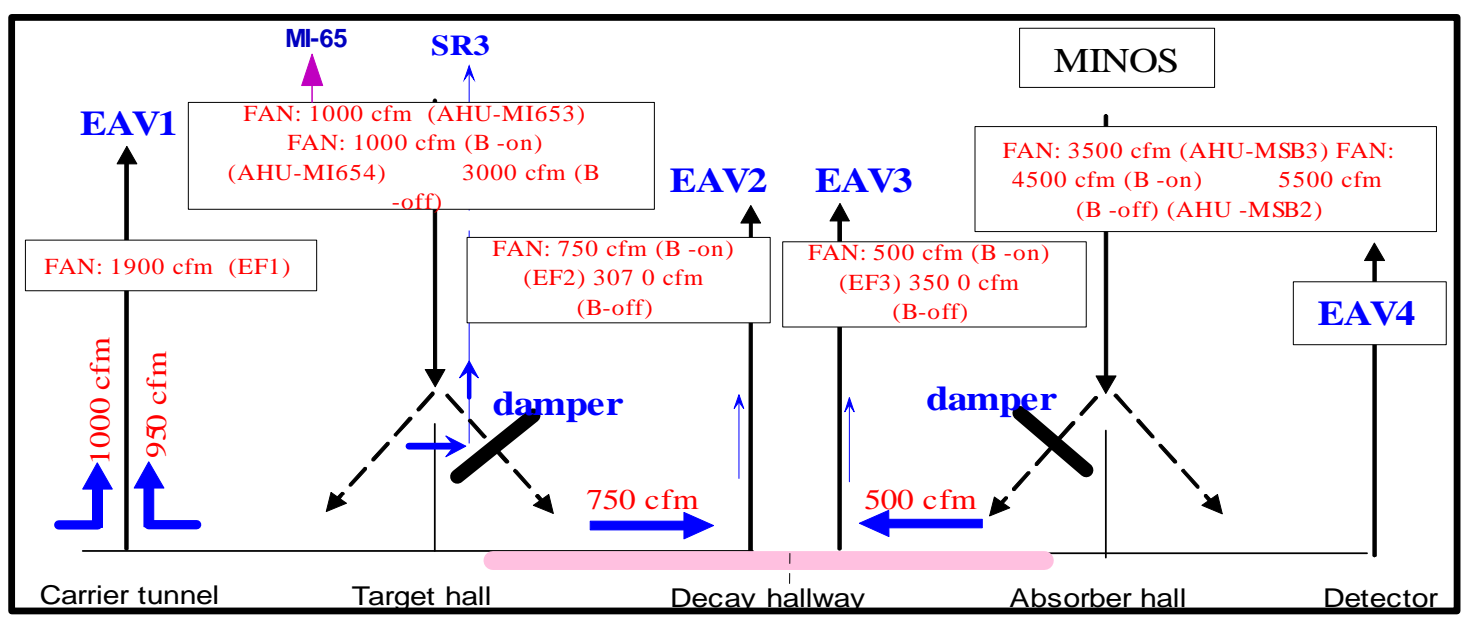

Figure 2. Schematic drawing of NuMI stacks and air flow rates under beam-on and beam-off conditions.

\section{Prompt Radiation}

There are several labyrinths and penetrations in the NuMI tunnels and halls for personnel access, connection to equipment, air inlets and exhausts, survey risers and an air-cooling labyrinth. Prompt radiation from the penetrations and labyrinths are estimated by calculations and extrapolation from measurements during the operation of NuMI. The 
results for these labyrinths and penetrations are given in the Table 4 and discussed in the following sections. Dose rates due to losses under normal and accident conditions are given. An accident, where credible, is defined as five sequential full intensity proton pulses lost. Normal losses depend on the location. Near the target and baffles it is full beam loss during an hour and assumed $0.01 \%$ of the full beam at other locations.

\section{Survey Risers 1, 2 and 3}

The calculated accident dose rate at the exit of SR-1 is $113 \mathrm{mrem} / \mathrm{hr}$. The existing plug, which is combined $3 \mathrm{ft}$. iron and $1 \mathrm{ft}$. concrete, will reduce the accident dose rate to less than 50 micro-rem/hr. At this reduced dose rate no radiological posting is required. The plug will also reduce the dose rate due to normal losses to the same classification.

SR-2 plug is a combined $2 \mathrm{ft}$. iron and $1 \mathrm{ft}$. concrete. The plug will reduce the exit dose rate from normal beam losses and the accidental losses to below 50 micro-rem/hr. SR-3 also functions as a stack and does not have a shield plug. There is no credible accident case under the SR-3 opening that can produce losses which are larger than the normal losses. Dose rate measurements at 2.8E16 protons/hr showed only background rates of less than $0.05 \mathrm{mrem} / \mathrm{hr}$ under normal conditions. These results were extrapolated to 500 $\mathrm{kW}$ operations as upper limit dose rates.

\section{Air exhaust stacks EAV-1, EAV-2 and EAV-3}

The accident dose rates at the exit of EAV-1 are insignificant. There are no credible accident cases under the EAV-2 and EAV-3 openings that can produce losses which are larger than the normal losses. Dose rate measurements at 2.8E16 protons/hr showed only background rates of less than $0.05 \mathrm{mrem} / \mathrm{hr}$ under normal conditions. These results were extrapolated to $500 \mathrm{~kW}$ operations as upper limit dose rates.

\begin{tabular}{|c|c|c|c|c|}
\hline \multirow[t]{3}{*}{ Region } & \multicolumn{2}{|c|}{ Normal Loss } & Accidental & \\
\hline & $\begin{array}{l}\text { Exit Dose } \\
\text { Rate } \\
\text { unshielded }\end{array}$ & & $\begin{array}{c}\text { Exit Dose Rate } \\
\text { unshielded }\end{array}$ & \\
\hline & (mrem/hr) & Comment & (mrem/hr) & Comment \\
\hline Survey Riser SR-1 & $4.3^{*}$ & existing plug mitigates & $113^{*}$ & $\begin{array}{l}\text { existing plug } \\
\text { mitigates }\end{array}$ \\
\hline Air Vent EAV-1 & $0.17 * *$ & OK (loss rate $1 \mathrm{E}-4)$ & $<0.001^{*}$ & $\mathrm{OK}$ \\
\hline Survey Riser SR-2 & $0.3^{*}$ & existing plug mitigates & 7* & $\begin{array}{l}\text { existing plug } \\
\text { mitigates }\end{array}$ \\
\hline $\begin{array}{l}\text { Target Hall } \\
\text { labyrinth }\end{array}$ & $0.005^{*}$ & $\mathrm{OK}$ & $0.1^{*}$ & $\mathrm{OK}$ \\
\hline $\begin{array}{l}\text { Target Hall } \\
\text { Equipment Door }\end{array}$ & 0.2 & $\begin{array}{l}\text { Post as Controlled } \\
\text { Area Min. Occup. }\end{array}$ & 0.1 & $\mathrm{OK}$ \\
\hline $\begin{array}{l}\text { Strip line } \\
\text { Penetration }\end{array}$ & 0.1 & $\begin{array}{l}\text { Existing shielding } \\
\text { mitigates }\end{array}$ & & \\
\hline RAW Penetration & $0.1^{*}$ & $\begin{array}{l}\text { Pipes will fill voids. } \\
\text { Area inaccessible }\end{array}$ & & \\
\hline
\end{tabular}




\begin{tabular}{|l|c|l|l|l|} 
Survey Riser SR-3 & $0.17^{* *}$ & Controlled Area & & \\
\hline Vent EAV-2 & $0.17^{* *}$ & Controlled Area & & \\
\hline Vent EAV-3 & $0.17^{* *}$ & Controlled Area & & \\
\hline Absorber Labyrinth & 2.1 & $\begin{array}{l}\text { Post as Controlled } \\
\text { Area Min. Occup. }\end{array}$ & & \\
\hline Muon Alcove 2 & 21.4 & $\begin{array}{l}\text { Door posted and } \\
\text { interlocked }\end{array}$ & & \\
\hline Muon Alcove 3 & 2.1 & $\begin{array}{l}\text { Door posted and } \\
\text { interlocked }\end{array}$ & & \\
\hline Muon Alcove 4 & 0.2 & $\begin{array}{l}\text { Door posted and } \\
\text { interlocked }\end{array}$ & & \\
\hline $\begin{array}{l}\text { MINOS Hall } \\
\text { (muons) }\end{array}$ & $0.17^{* *}$ & $\begin{array}{l}\text { Controlled Area } \\
\text { Move radiological } \\
\text { boundary or post }\end{array}$ \\
\hline $\begin{array}{l}\text { Bypass } \\
\text { tunnel(muons) }\end{array}$ & 0.11 & & \\
\hline
\end{tabular}

Table 4. Dose rates at the exit and mitigation where needed for the NuMI labyrinths and penetrations. If no accidental losses (as defined) are possible, no estimates are given. * denote extrapolation from calculations. ** denotes locations where measurements showed zero dose, extrapolations were done from the detector minimum detection threshold.

Based on the combined dose rates from EAV-2 and EAV-3, the area around these two adjacent stacks does not need to be posted, but it is classified as Controlled Area with minimal occupancy.

\section{Target Hall labyrinth}

In addition to radiation propagating through the legs of this labyrinth there is a significant contribution to the radiation field in the second leg due to leakage through the wall (the so called short circuit). This leakage dose rate is calculated as an additional source term. The resulting dose at the exit is added to that originated at the entrance to the first leg. The dose rates under both the normal and accident conditions are low enough that the exit of this labyrinth requires no posting.

\section{Target Hall equipment door}

The target hall is not accessible during beam operations. There is a $10 \mathrm{ft}$. concrete door blocking the direct access to the hall. Based on the measurements the dose rate immediately outside the door is $0.2 \mathrm{mrem} / \mathrm{hr}$. The classification for this area would be Controlled Area. Given the location of this area, it is naturally a limited occupancy area.

\section{Horn strip-line penetration}

The section of the penetration between the horn and the top of the module is not considered here, since the target hall is not accessible during the beam operation. Only the section of penetration between the target hall and the power supply room is needed to calculate the dose to personnel in the power supply room. The source term is calculated at the entrance to this penetration using MARS. The penetration is modeled as empty, but it 
is partially filled with the strip-line material which occupies about $10 \%$ of the cross sectional area. The neutron spectrum at the entrance to this penetration is mainly composed of neutrons of energy less than $1 \mathrm{MeV}$. Polyethylene is an effective absorber of these neutrons. Since the rest of the penetration cannot be filled completely, polyethylene sheets have been used near the entrance and exit of this penetration to shadow the penetration to effectively reduce the dose rates. The dose rate at $200 \mathrm{~kW}$ for the unshielded penetration was expected to be $68 \mathrm{mrem} / \mathrm{hr}$. Measurements near the shielded penetration has been consistently detecting very small amount of leakage radiation. The extrapolated dose rate for the $500 \mathrm{~kW}$ case is $0.1 \mathrm{mrem} / \mathrm{hr}$.

\section{RAW systems penetration}

MARS calculations provided the source term at the entrance to this penetration. Similar to the horn strip-line, the section of penetration between the target hall and the RAW room is used to calculate the dose to personnel in the RAW room. This penetration is 95\% filled with RAW pipes filled with water, which reduces the amount of radiation leakage greatly. Water is a much more effective shield against low energy neutrons than concrete. As Table 4 shows, the dose rate from the filled penetration is small. Additionally the RAW room is not accessible during the beam operations.

\section{Hadron Absorber access labyrinth}

Figure 3 shows the layout of this labyrinth. Since access to the hadron absorber area is controlled at the fire door, the dose rates are measured at the door. Some of the concrete bricks used on top of the blocks or along the walls have a density of $1.44 \mathrm{~g} / \mathrm{cm}^{2}$. In addition to the labyrinth, there are two possible short circuit paths; through the $6 \mathrm{ft}$. concrete section and the $9 \mathrm{ft}$. section. The leakages through these two pathways are added to the dose from the labyrinth. The resulting extrapolated dose rate is $2.1 \mathrm{mrem} / \mathrm{hr}$. This section of the bypass tunnel is classified as minimal occupancy Controlled Area. 


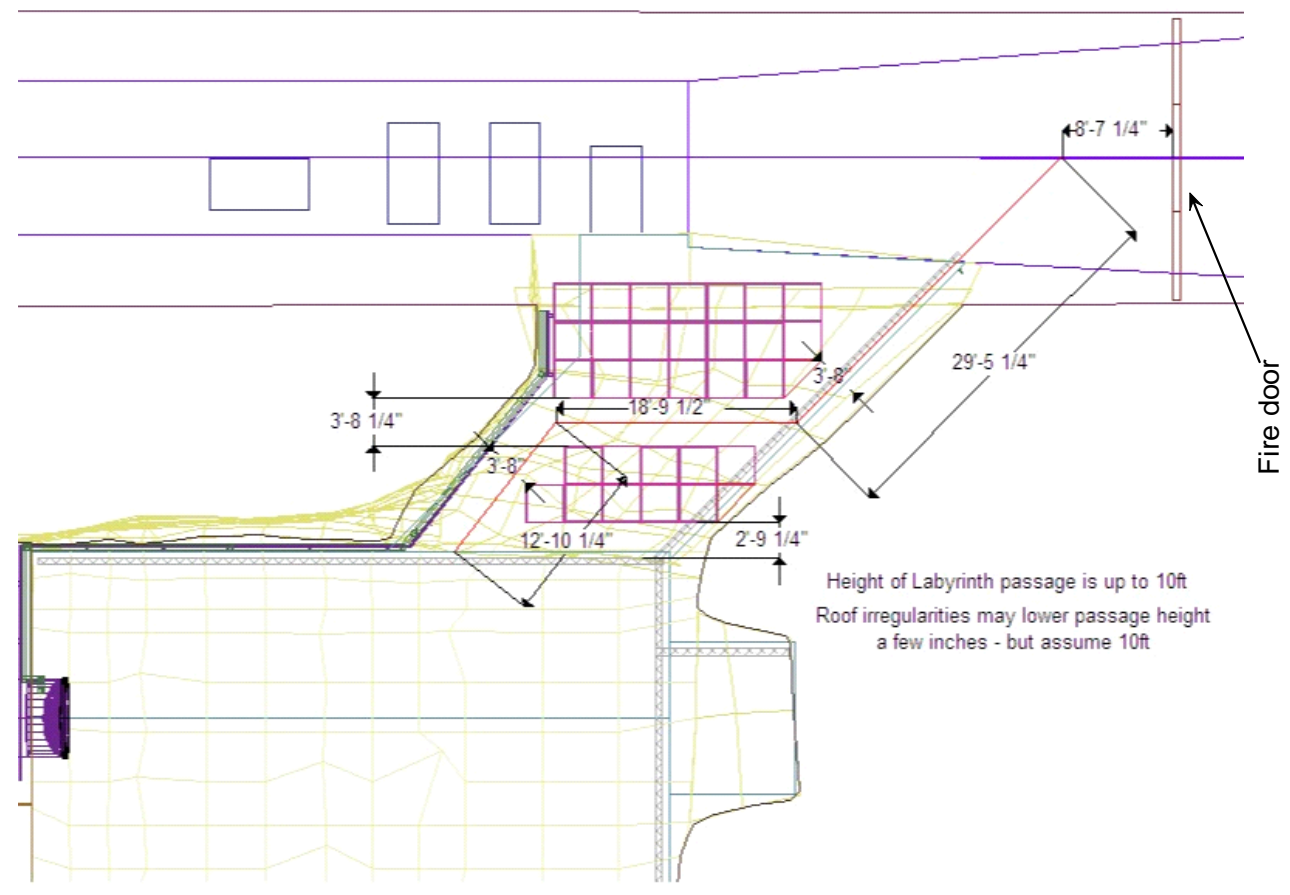

Figure 3. Schematic drawing of the hadron absorber, access labyrinth and the bypass tunnel.

\section{Beam-on dose rate at the gate to the Muon-Alcoves 2, 3 and 4}

The dose rate extrapolated from measurements at the exit of Muon-Alcove 2 at $500 \mathrm{~kW}$ is $21.4 \mathrm{mrad} / \mathrm{hr}$. However, additional shielding in front of the gate has reduced the extrapolated dose to $4.3 \mathrm{mrad} / \mathrm{hr}$. The highest extrapolated dose at the exit of MuonAlcove 3 and 4 are $2.4 \mathrm{mrad} / \mathrm{hr}$ and $0.2 \mathrm{mrad} / \mathrm{hr}$, respectively.

These results for $500 \mathrm{~kW}$ indicate that the area near alcove- 2 gate is classified as Radiation Area and alcoves 3 and 4 as Controlled Area, minimal occupancy. 


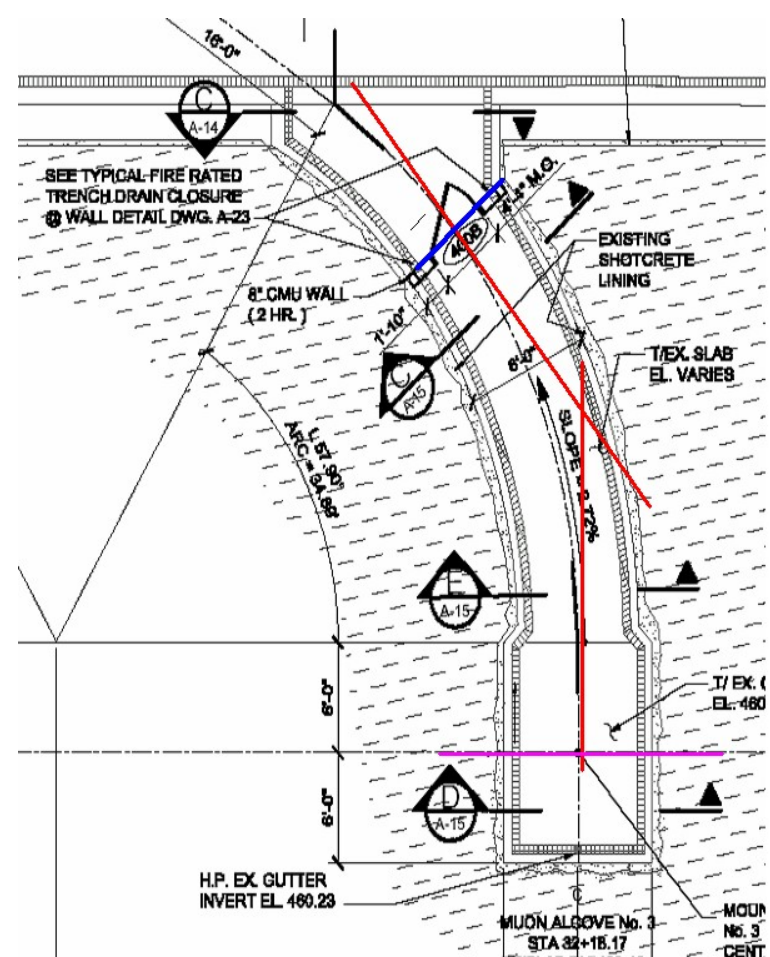

Figure 4. An example of a two-leg approximation to a curved labyrinth. The red lines show the straight leg approximation. Leg 1 starts at centre of the alcove to where it crosses the second leg (red line). Leg 2 is defined from the intersection to the gate of the alcove.

\section{Door of the RAW room}

Figure 5 shows the NuMI RAW room where the primary water-cooling systems for the horns, target and the decay pipe are located. The dose rate at the door is due to the radiation leaking through the concrete wall, through the gaps between the top of the walls and the rock ceiling and through the RAW room doorway. Table 5 gives the radioactivity concentrations in the tanks and the resulting dose rate at the door due to each one of the systems after one year of operation at $500 \mathrm{~kW}$. About $90 \%$ of this dose is from the opening between the top of the walls and the rock ceiling.

\begin{tabular}{|l|c|c|c|c|c|}
\hline RAW Source & Horn1 & Horn2 & Target & Decay Pipe & Total \\
\cline { 2 - 6 } & $8.29 \mathrm{E}+06$ & $2.45 \mathrm{E}+06$ & $3.09 \mathrm{E}+06$ & $4.10 \mathrm{E}+03$ & (mrem/hr) \\
\hline $\begin{array}{l}\text { (Bq/ml) } \\
\text { Dose rate at } \\
\text { door }\end{array}$ & $9.57 \mathrm{E}-01$ & $2.62 \mathrm{E}-01$ & $1.06 \mathrm{E}-01$ & $1.39 \mathrm{E}-03$ & $\mathbf{1 . 3}$ \\
\hline
\end{tabular}

Table 5. Radioactivity concentrations of various RAW systems after one year of $500 \mathrm{~kW}$ operations and the expected dose rate at the door of the RAW room.

The total dose rate of $1.3 \mathrm{mrem} / \mathrm{hr}$ is a conservative estimate based on one-year full intensity operation without any time to cool down. No credit is taken for the shielding due to all the pipes, I-beams and other equipment. Most of ${ }^{7} \mathrm{Be}$ will be trapped in the DIbottles and filters, which are locally shielded. Seventy percent of the activity is due to the isotope ${ }^{15} \mathrm{O}$, which has a 2-minute half-life. A 2-minute transit time from the target hall to the tank can reduce the above rates by $30 \%$. Based on the above assumptions and results, 
the area outside the door should be posted as Controlled Area with Minimal Occupancy classification.

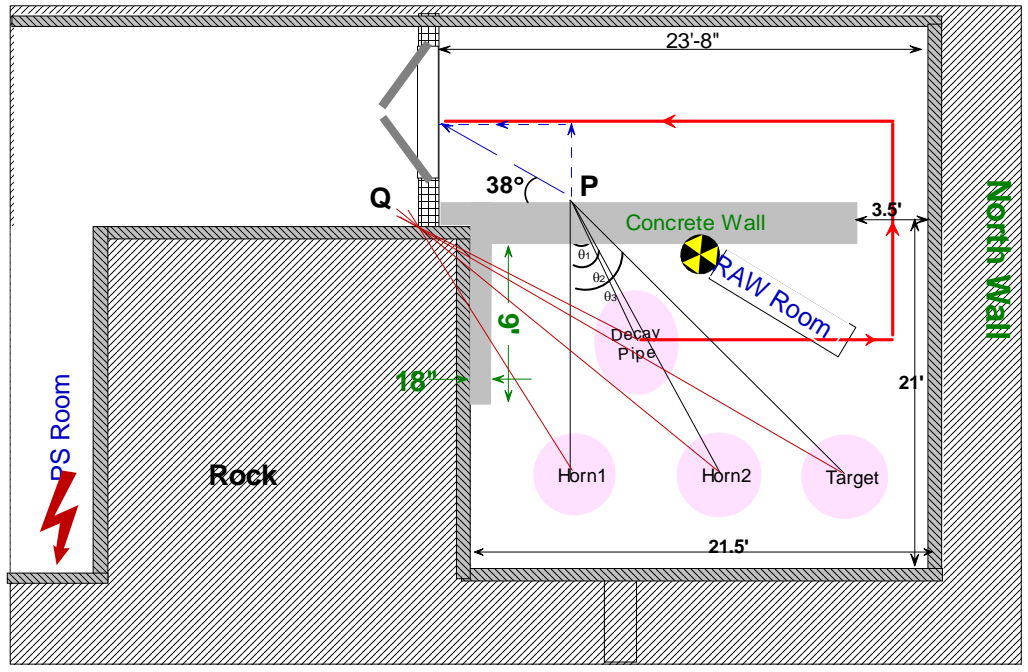

Figure 5. Plan view of the RAW room. Point Q is the location of the highest dose rate at the door. The red line shows an example of path from one of the sources through the labyrinth.

\section{Target Chase Air Cooling Labyrinth}

The exit of this labyrinth is in the target hall and is not accessible during the beam operations.

\section{MINOS access shaft and EAV-4}

The dose rates at the base of the MINOS access shaft and in the MINOS hall are negligible. No measurable radiation dose rate due to the $500 \mathrm{~kW}$ beam operations is expected at the top of the MINOS access shaft or the EAV-4 stack.

\section{Muon rates}

Muon dose rate at the bypass tunnel across from the Muon Alcoves- 2 is estimated at about $0.6 \mathrm{mrem} / \mathrm{hr}$. However, as mentioned above, measurements showed high dose rates in this area, and the relatively small muon dose rate was not easily identifiable. In the MINOS Hall no muon dose rates above the background was detected. The background values were extrapolated to $500 \mathrm{~kW}$ operations as upper limit dose rates. Thus that defines the end of the area of radiological concerns.

\section{NuMI Residual Dose Rates}

The residual radiation field is that which remains after the beam has been shut down. In most situations at Fermilab the residual radiation field is almost exclusively gamma and beta rays. Residual dose rates are highest for longer irradiation times, shorter cool down 
times, and closer distances to the component of interest. Steel, concrete and aluminum are the major materials in the NuMI beam line. Since steel cools down slower than the other two, so is typically the driving material for the residual dose rate for a given component or area of the Target Hall. The standard residual rate values quoted are for a 30-day irradiation and a 1 day cool down on contact, designated (30d, 1d). Thus values for (30d, 1d) at operations with $400 \mathrm{~kW}$ and $500 \mathrm{~kW}$ beam power are given. For a given irradiation time and cool down time, values roughly scale with beam power. For components within the target chase, cool down times of 1 week are probably more realistic since it usually takes several days to access the chase.

Residual dose rates for $500 \mathrm{~kW}$ are best estimated by extrapolating from NuMI measurements which correspond to approximately $170 \mathrm{~kW}$ beam. The simulation program MARS ${ }^{15}$ can be used to determine the scaling factor needed to go from the measured numbers for a $170 \mathrm{~kW}$ beam to $500 \mathrm{~kW}$ beam.

\section{Residual rate estimates for $500 \mathrm{~kW}$ NuMI}

Measurements of NuMI residual rates for some Target Hall components were taken during the March 2006 shutdown. For reference, Figure 6 shows components and shielding around horn 1. By March NuMI had taken 1.4E20 protons on target (POT) or an equivalent of 0.28 years of 5E20 POT/yr running. The scale factor from 0.28 years to 2.25 years (10.2E20 protons on target) of running for the steel and horn 1 endcap are approximately 1.5 based on cooling curves in reference 16 . Conservatively we can assume a factor of 2 higher residual rates for these components by 2009. March shutdown measurements taken after 3 days of cool down at three locations; (1) Horn 1, (2) Above the module near the ears (where shielding is light), and (3) On top of the Tblocks and gave rates of $80 \mathrm{R} / \mathrm{hr}, 200 \mathrm{mR} / \mathrm{hr}$ and 75mR/hr respectively (see Fig. 6 and Table 6). MARS predictions for the horn are $160 \mathrm{R} / \mathrm{hr}$ and $\sim 80 \mathrm{R} / \mathrm{hr}$ for the steel around it. Thus the measured and predicted rates for Horn 1 are considered consistent.

However, the value for the top T-blocks predictions ${ }^{16}$ are closer to $4 \mathrm{mR} / \mathrm{hr}$ versus the 75 $\mathrm{mR} / \mathrm{hr}$ measured. Thus values on top of the T-blocks (below the R-Blocks) are considerably higher than estimated by MARS. This is thought to be due to the thin shielding and the cracks in the "ears" of the module which was not precisely modeled in the MARS calculations. Extrapolating from these values one would expect about two times higher rates by 2009 for these steel components. Thus the levels above the Horn 1 T-blocks could be as high as $300 \mathrm{mR} / \mathrm{hr}$. To mitigate the rising dose rates, a platform will be built to cover the top of the T-blocks around the horn area after the R-blocks are removed remotely. This platform could be placed remotely and will be designed to reduce the radiation levels to a reasonable level for the amount of work that needs to occur in that area.

Another set of measurements was taken near the target on 4/8/06 after 6 weeks of cool down. Measurements at the bottom of the target module yielded levels of $50-150 \mathrm{mR} / \mathrm{hr}$. Measurements near the hottest spot on target (as close as one could reach) yielded levels up to $1.2 \mathrm{R} / \mathrm{hr}$ at 2 " from the target. The module, being of steel, should scale as the Tblock values. Using reference 16, MARS values for the bottom of the T-blocks 30 day cooling curve, the value predicted by MARS (granted this is for the horn 1 module), is 
$\sim 100 \mathrm{R} / \mathrm{hr}$ on contact and scales to $\sim 175 \mathrm{R} / \mathrm{hr}$ after 2.25 years of running, or a factor of 1.75 higher. Thus one would expect these levels around the target module to increase to 100 to $375 \mathrm{mR} / \mathrm{hr}$ on contact (for a similar cool down time). The level of $1.2 \mathrm{R} / \mathrm{hr}$ near the target, if it was from steel components, might also scale by this factor (1.75). Target and horn replacement work is done remotely, thus these levels are not of great concern. Greater care will need to be taken when transporting radioactive components to the work cell and morgue, using temporary shielding for personnel as necessary.

Measurements on 3/20/06 after 3 weeks of cool down were taken of Horn 2 on contact at the downstream end and yielded levels of 5-8 R/hr. If these were due to steel activation, they would scale by a factor of $\sim 1.5$. The horn, being aluminum, cools down rather quickly in a week and then one does not gain much after that, as shown in reference 16. The aluminum would scale up by a factor of $\sim 1.4$ from present measurements to a similar cool down time at the last shutdown in 2009. Table 6 summarizes the estimated residual dose rates

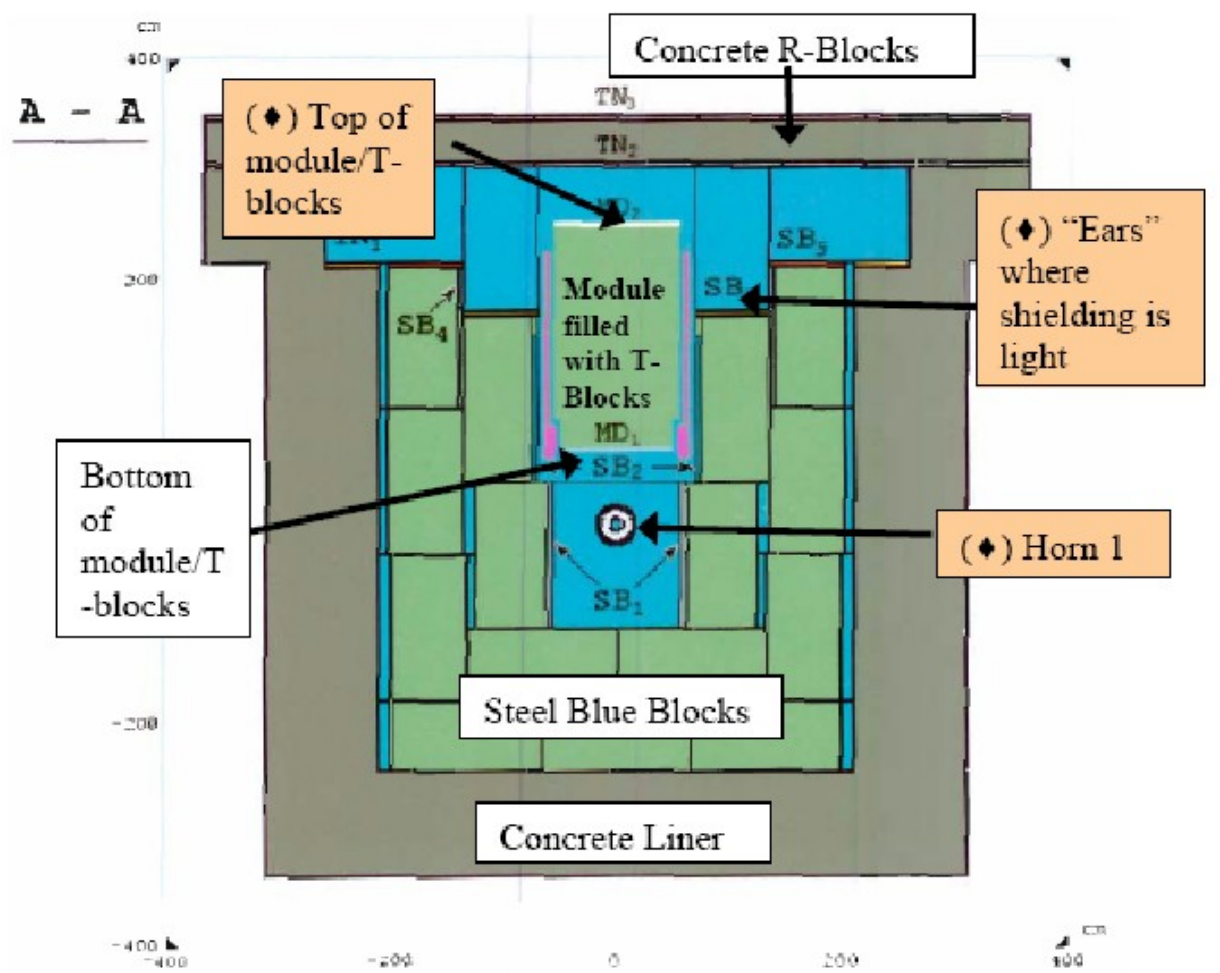

Figure 6. Cross Section of NuMI Target Hall, Component Region. As referred to in the text, the locations marked with $(\bullet)$ are where the radiation dose rates were measured during the March 2006 shutdown. 


\begin{tabular}{|l|c|c|c|c|c|c|l|l|l|}
\hline & & & & & & $\begin{array}{l}\text { Above } \\
\text { Horn 1 } \\
\text { Module, } \\
\text { by "ears" } \\
\text { (mrem'hr) }\end{array}$ & $\begin{array}{l}\text { Horn 1 T- } \\
\text { Blocks } \\
\text { Top } \\
\text { (mrem/hr) }\end{array}$ & $\begin{array}{l}\text { Horn 2 } \\
\text { (R/hr) }\end{array}$ \\
\hline $\begin{array}{l}\text { Time } \\
\text { PARS } \\
\text { predicted }\end{array}$ & $1.40 \mathrm{E}+20$ & 400 & & & & 160 & 4 & 4 & \\
\hline $\begin{array}{l}\text { Spring 2006 } \\
\text { shutdown }\end{array}$ & $1.40 \mathrm{E}+20$ & 120 & 1 & 1.20 & 50 to 150 & 80 & 200 & 75 & 5 to 8 \\
\hline $\begin{array}{l}\text { Spring 2009 } \\
\text { shutdown }\end{array}$ & $1.02 \mathrm{E}+21$ & $250-500$ & 1.2 to 2 & 3.00 & 100 to 375 & 150 & 375 & 138 & 8 to 15 \\
\hline
\end{tabular}

Table 6. Summary of Residual Dose Rate Predictions for NuMI

\section{Hydrogen gas evolution from the RAW systems}

For the calculation of the hydrogen gas production ${ }^{3}$ in the volume between the conductors, the MARS energy deposition calculations in the aluminum conductors was averaged and scaled down to the density of water. Energy deposition prediction in the retention tank area was not available. The energy deposition in the water between the two conductors was scaled down according to the hadron flux reduction, going from between the conductors to the retention tank area. The results of the calculations are shown in Table 7.

The amount of hydrogen gas produced in the horn RAW systems is significant enough that the RAW tanks are continuously purged with argon gas. Release of this hydrogen in the RAW room will results in hydrogen concentrations two orders of magnitude less than required for an explosive mixture.

\begin{tabular}{|c|c|c|c|c|}
\hline & $\begin{array}{l}\text { Gallons of } \\
\mathrm{H}_{2} / \text { year }\end{array}$ & \begin{tabular}{|l|} 
Gallons of \\
$\mathrm{H}_{2} /$ day
\end{tabular} & $\begin{array}{l}\text { Gallons of } \\
\text { water } \\
\text { lost/yr }\end{array}$ & \\
\hline & \begin{tabular}{|l|}
100.25 \\
\end{tabular} & 0.25 & 0.0375 & Horn-1 \\
\hline & 215.125 & 0.625 & 0.0875 & Retention tank-1 \\
\hline \multirow[t]{3}{*}{ TOTALS= } & 315.375 & 0.875 & 0.125 & \\
\hline & 8.625 & 0 & 0 & Horn-2 \\
\hline & 50.125 & 0.125 & 0.025 & Retention tank-2 \\
\hline TOTALS= & 58.75 & 0.125 & 0.025 & \\
\hline
\end{tabular}

Table 7. Predicted hydrogen gas evolution due to radiolysis from Horn-1 and Horn-2 RAW systems.

\section{Radioactive component handling}

The original NuMI Target Hall Work Cell and associated Radioactive Component Removal Plan were developed with 2 key concepts in mind. The first was that components (Target/Baffle, Horn 1 \& Horn 2) would not be repaired in the Work Cell, but only replaced. The second was that failed, radioactive components would be stored 
long term in a shielded pit, called "the Morgue" with no plans for radioactive component removal up-shaft for disposal. Practical lessons learned from 1-1/2 years of operational experience of NuMI have altered those concepts. Necessity of more complex repairs than originally envisioned have required installation of additional shielded structures (a shield wall with an access window), and hot component handling procedures for radioactive component removal. These changes were needed even though residual dose rates of components are estimated reasonably correct. Similar procedures will be used at $500 \mathrm{~kW}$.

\section{Radioactive waste disposal}

The tritiated water from the RAW systems and the Target Chase air chiller condensate are solidified and disposed of as solid low level radioactive waste. Some broken components will be stored in the "morgue" in the Target Hall, until preparations are made for safe storage at another location on site, or disposal. Other items that can be taken up the access shaft are characterized and disposed of as solid low level radioactive waste.

\section{Conclusion}

The shielding of the NuMI $120 \mathrm{GeV}$ beam line from Q608 to the end of the MINOS Hall is adequate to allow for continuous targeting of up to $5 \mathrm{E} 13120 \mathrm{GeV}$ protons/1.87 seconds. Air activation, groundwater concentrations and muon production along the beam line are all within the FRCM guidelines. RAW water activation levels in the horn 1 RAW system are anticipated to be above FRCM guidelines. Changing it at the frequency necessary to keep it below FRCM guidelines would not be ALARA. It will be changed out approximately annually. All other RAW system activity levels will be within FRCM guidelines. Residual dose rates for elements along the beam line and outside the target pile are typical and controlled using standard Accelerator Division operating procedures. Estimates of dose rates have been made and procedures have been written for changing out a radioactive component in the Target Hall. Additional requirements for repairs are handled on a case by case basis. An interlocked radiation monitor at the upstream end of the pretarget is used to minimize beam loss in the primary beam. The integrated proton beam intensity transmitted down the NuMI Beam line will be recorded by the Beam Budget Monitor as programmatically required.

\section{References:}

1. NuMI Safety Assessment Document 11/1/2004.

2. Main Injector Shielding Assessment, October 2004

3. NuMI shielding Assessment 9/4/2004. 
4. F. Breen, "Evaluation of Boundary Conditions for the Two Dimensional Groundwater Model Simulations, Earth Tech Draft Groundwater Modeling Report, dated, May, 1999”, Technical Memorandum, June 12, 1999; Earth Tech, Inc., “Two Dimensional Groundwater Flow Model, Results Estimated Inflow to NuMI Tunnel”, NuMI Tunnel Modeling Project Report, August 1999; Breen GeoScience Inc., "NuMI 3D Groundwater Model Update”, August 2004.

5. N. Grossman, G. Rameika, "Methodology for Determining Radionuclide Concentration in Groundwater in the Vicinity of Accelerator and Beam line Enclosures”, NuMI Note 970, July 2004.

6. Fermilab Radiological Control Manual. - The current web link is: http://www-esh.fnal.gov/home/esh_home_page.page?this_page $=900$

7. NuMI Beam Permit System Inputs (xls)- Feb 5, 2004 for beam system inputs and tolerance levels.

8. P. Kesich, J.D. Cossairt, “The Groundwater Monitoring Strategy for NuMI”, NuMINOTE-Beam-967, Dec. 2003; ES\&H Section, Environmental Protection Team, Environmental Protection Procedures Manual, Procedures 100, 105, 109.

9. “Beams Division Routine Monitoring Program”, BDDP-SH-1003, Rev 0.

10. Radioisotope Analysis Facility reports December 11, 2004

EPG 06-722 S-1274 (Low Level) gamma

EPG 06-743 S-1274 (Low Level) gamma

EPG_Ground Water_06-722

EPG_Ground Water_06-743

11. Stephen Pordes, "A summary of present Calculations on Tritium Production and Mobility in the NuMI Decay Pipe”, Fermilab-TM-2378, April2007.

12. K. Vaziri “IronLeachateResults_v2.xls “,Projects-doc-118-v2, 17 Oct 2006.

13. Kamran Vaziri, "NuMI RAW Systems Containment Plans”, NuMI Note 1009, July 2004.

14. N. Grossman and D. Harris “NuMI Muon Rates” March 2004, -updated July 2004. NuMI Note 1025

15. N.V. Mokhov, "The MARS Code System User's Guide", Fermilab-FN-628 (1995); N.V. Mokhov, O.E. Krivosheev, "MARS Code Status", Proc. Monte Carlo 2000 Conf., p. 943, Lisbon, October 23-26, 2000; Fermilab-Conf-00/181 (2000); N.V. Mokhov, "Status of MARS Code", Fermilab-Conf-03/053 (2003). 
16. N. Grossman, “Residuals Estimates for SNuMI”, SNuMI Docdb \#39, October 2006.

17. K. Vaziri, "Radiological issues associated with venting tritiated air from NuMI SR3”, February 2007.

18. K. Vaziri, “Tritium Release from NuMI MI-65 Stack” April 2007.

19. K. Vaziri, "Radiological issues associated with helium in the NuMI Decay Pipe for a $500 \mathrm{~kW}$ beam” October 2007. 